\title{
Environmental hazards and demographic and clinical data of childhood interstitial lung diseases in a tertiary institute in Egypt
}

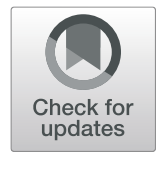

\author{
Sally Raafat Ishak ${ }^{1 *}$, Azza Mohammed Hassan² and Terez Boshra Kamel ${ }^{1}$
}

\begin{abstract}
Background: The incidence of childhood interstitial lung diseases increased in the last years in Egypt. Changes in environmental and climatic conditions may be contributing factors. Also, raising birds at home increased in the past years due to financial issues. Other environmental factors include increased industries, traffic, and pollution. Our study aimed to assess the environmental hazards and the severity of childhood interstitial lung diseases.

Results: Sixty-five percent of patients with childhood interstitial lung diseases (chILD) were exposed to cigarette smoke; $45 \%$ were exposed to birds, 30\% to industrial wastes, $20 \%$ to grass and pesticides, and $10 \%$ to animals.
\end{abstract}

Conclusions: Exposure to cigarette smoke and birds increases the risk of development of chILD.

Keywords: Childhood interstitial lung disease, Birds, Egypt, Environmental factors

\section{Background}

Interstitial lung disease (ILD) defines any disease that affects the interstitium and the distal alveoli of the lungs, leading to impaired lung diffusion. In pediatrics, the disease may also include affection of the airways, vascular, and lymphatic vessels [1]. The prevalence of pediatric ILD is estimated to be 3.6 and 1.32 per million in the UK and Germany, respectively [2], but there are no recorded studies for its prevalence in Egypt. Mortality from childhood interstitial lung diseases (chILD) ranges from 15 to $60 \%$ in different research reaching up to $100 \%$ in genetic and developmental causes [3].

Although the cases diagnosed as chILD increased in the past years in Egypt, there is no available data for the demographic data of these patients and the possible environmental conditions that aid in increasing their prevalence.

Several environmental exposures have a key role in the etiology of chILD. Cigarette smoke is a studied factor.

\footnotetext{
* Correspondence: Sally.raafat@med.asu.edu.eg

${ }^{1}$ Pediatric Department, Faculty of Medicine, Ain Shams University, Cairo

11591, Egypt

Full list of author information is available at the end of the article
}

"Smoking-related interstitial lung disease" is a pathological term used to describe lung biopsies with findings suggestive of desquamative interstitial pneumonia (DIP), Langerhans' cell histiocytosis, and respiratory bronchiolitis-interstitial lung disease (RB-ILD) [4].

Hypersensitivity pneumonitis (HP) or extrinsic allergic alveolitis is another known subtype of chILD resulting from exposure to different organic or inorganic dusts of bird, animal, or plant origin. In genetically susceptible persons, sensitization to inhaled dust induces in the alveolar and interstitial space an inflammatory reaction that affects gas exchange. In children these diseases are often due to exposure to antigens present in the domestic environment [2].

In many parts of the world especially in rural areas and in developing countries, the exposure to fire smoke is a recognized cause of interstitial lung disease. Burning trashes occurs in Egypt in the season of harvesting rice and causes black cloud in the sky of Egypt during this season which may affect the lungs of genetically predisposed subjects [5].

Our study aimed to determine the demographic data and the most common environmental factors affecting

\section{Springer Open}

(- The Author(s). 2021 Open Access This article is licensed under a Creative Commons Attribution 4.0 International License, which permits use, sharing, adaptation, distribution and reproduction in any medium or format, as long as you give appropriate credit to the original author(s) and the source, provide a link to the Creative Commons licence, and indicate if changes were made. The images or other third party material in this article are included in the article's Creative Commons licence, unless indicated otherwise in a credit line to the material. If material is not included in the article's Creative Commons licence and your intended use is not permitted by statutory regulation or exceeds the permitted use, you will need to obtain permission directly from the copyright holder. To view a copy of this licence, visit http://creativecommons.org/licenses/by/4.0/. 
the children and adolescents with childhood interstitial lung disease in Egypt.

\section{Methods}

A cross-sectional study was done on 40 patients with interstitial lung diseases attending the Pediatric Chest Clinic, Children's Hospital, Ain Shams University. The study was undergone from September 2018 to November 2019 .

\section{Inclusion criteria}

chILD was diagnosed by the presence of 3 out of 4 of the following criteria [6]:

1. Symptoms of impaired respiratory function (dyspnea, cough or exercise intolerance)

2. Signs (tachypnea, adventitious sounds, retractions, clubbing, failure to thrive, or respiratory failure)

3. Radiological findings suggestive of interstitial lung disease (e.g., lung infiltrates, ground glass appearance)

4. Restrictive lung disease in pulmonary functions or evidence of hypoxemia (resting hypoxemia or desaturation with exercise)

\section{Exclusion criteria}

Any Interstitial lung disease due to a known cause as collagen vascular diseases, post-chemotherapy or radiotherapy, postinfection, or genetic causes.
Approval of the medical ethical committee of Children's Hospital, Ain Shams University, was taken first; also, a verbal and written informed consent was taken from all subjects' care givers prior to the study.

All children were subjected to complete history taking; with special emphasis on age, sex, age of onset of symptoms, family history, exposure (drug, smoking, environmental exposure), and previous hospital admission (their cause and frequency).

The severity of chILD was assessed by:

1. Dyspnea was assessed with the modified Medical Research Council (MRC) dyspnea scale score $(6$ points) that consists of six questions about their subjective dyspnea [7].

2. The high-resolution CT Score of ILD [8].

3. ILD severity of illness score [6].

4. Six-minute walk test $[9,10]$.

5. Oxygen saturation by pulse oximeter. Desaturation in children with ILD was defined as oxygen saturation by pulse oximetry below $93 \%$ [11].

6. Spirometry: It was performed for only cooperative children, above 7 years of age (26 patients) using VIASYS Healthcare GmbH. Leibnizstrasse 7 to measure the forced expiratory volume in first second (FEV1) and forced vital capacity (FVC) expressed as percentage of the predicted value for age, sex, weight, and height.

7. Diffusion capacity of carbon monoxide (DLCO). Only 12 patients were able to perform the

Table 1 Demographic data of Egyptian patients with chILD

\begin{tabular}{|c|c|c|c|}
\hline & Minimum & Maximum & Mean (SD) \\
\hline Age of onset (years) & 0.50 & 13.00 & $5.83(4.15)$ \\
\hline Disease duration (years) & 0.50 & 12.00 & $3.98(3.17)$ \\
\hline Frequency of hospital admissions per year & 1.00 & 7.00 & $2.28(1.75)$ \\
\hline MRC dyspnea score & .00 & 5.00 & $2.05(1.65)$ \\
\hline ILD severity score & 2.00 & 5.00 & $2.80(1.09)$ \\
\hline HRCT score & .00 & 3.00 & $1.85(0.92)$ \\
\hline Respiratory rate (breath/minute) & 15.00 & 78.00 & $35.30(16.53)$ \\
\hline Heart rate (pulse/minute) & 85.00 & 140.00 & $102.53(14.52)$ \\
\hline Oxygen saturation (\%) & 68.00 & 99.00 & $93.75(7.22)$ \\
\hline FEV1 (\% of predicted) & 24.80 & 77.20 & $53.66(14.42)$ \\
\hline FVC (\% of predicted) & 26.80 & 75.40 & $57.37(11.99)$ \\
\hline FEV1/FVC ratio (\% of predicted) & 55.00 & 111.40 & $91.64(16.22)$ \\
\hline DLCO-SB (\% of predicted) & 27.90 & 82.10 & $61.72(21.76)$ \\
\hline Total leukocyte count $\left(\times 10^{3} / \mu \mathrm{l}\right)$ & 3.30 & 26.80 & $9.70(5.44)$ \\
\hline Hemoglobin (g/dl) & 7.90 & 14.20 & $11.77(1.63)$ \\
\hline Platelets count $\left(\times 10^{3} / \mu \mathrm{l}\right)$ & 171.00 & 717.00 & $366.80(143.32)$ \\
\hline
\end{tabular}

$\overline{M R C}$ modified Medical Research Center, ILD interstitial lung diseases, HRCT high-resolution computerized tomography, FEV1 forced expiratory volume in $1 \mathrm{~s}$, FVC forced vital capacity, DLCO-SB diffusion of lung to carbon monoxide (single breath) 
technique due to the forced maneuver and the need to hold their breath for $10 \mathrm{~s}$ which could not be performed by the young and distressed patients.

\section{Statistical analysis}

Data were analyzed using Statistical Program for Social Science (SPSS) version 18.0.

Quantitative data were expressed as mean \pm standard deviation (SD). Qualitative data were expressed as frequency and percentage.

\section{Results}

Forty patients were included in the study. Their age ranged from 5 to 15 years old with the mean age of $9.7 \pm$ 3.09 years. The patients were 16 males $(40 \%)$ and 24 females (60\%). Demographic and clinical data of the studied patients are presented in Table 1.

Among the 40 studied patients, environmental exposure to passive cigarette smoking was the most frequent (65\%), followed by exposure to birds especially pigeons (45\%). Exposure to industrial wastes represented 30\% of the studied patients (divided into 10\% exposed to iron and cement industries, $5 \%$ to plastic industries, $5 \%$ to petroleum industries, and $10 \%$ to other industries). On the other hand, exposure to agricultural areas and pesticides represented $20 \%$, animals $10 \%$, paints $5 \%$, dust $5 \%$, and fire smoke $5 \%$ (Fig. 1).

The most frequent symptom among the studied patients was dyspnea (90\%), followed by cough (87.5\%), exercise intolerance (70\%), recurrent chest infection (50\%), chest pain (20\%), and expectoration (10\%). While among the physical signs, tachypnea was the most common sign (85\%) followed by crackles (70\%), clubbing (62.5\%), wheezes $(15 \%)$, cyanosis $(15 \%)$, accentuated second heart sound (15\%), and corpulmonale and heart failure (5\%). Only $10 \%$ of the patients were not dyspneic by modified MRC dyspnea score, while the rest had varying degree of dyspnea as shown in (Fig. 2).

Oxygen saturation at the rest of our patients ranged from 68 to 99 with a mean of $93.75 \pm 7.22$. Fifty-five percent of the patients were normoxemic at rest and after exercise (ILD score $\leq 2$ ), $25 \%$ became desaturated after six-minute walk test (ILD score $=3$ ), and $20 \%$ of them were desaturated at rest or have pulmonary hypertension (ILD score $\geq 4$ ) (Fig. 3).

Most of our patients (45\%) were given score 2 for their HRCT findings denoting moderate disease (traction bronchiectasis, peribronchovascular thickening, tracheal retraction involving one or two lobes of the lungs); then, score 1 was for $30 \%$ of the patients with minimal disease (ground-glass pattern, thickened interlobular septa, reticulonodular pattern and subpleural cysts), while 25\% had score 3 denoting severe disease (the findings in scores 1 and 2 involving 3 or more lung lobes) (Fig. 4).

Spirometry done by only 26 cooperative patients revealed a restrictive pattern in $88.5 \%$ of patients while only 3 patients $(11.5 \%)$ had a mixed obstructive and restrictive pattern. The DLCO done by 12 of our patients was ranging from 28.00 to $78.70 \%$ of the predicted normal values for age and sex, with a mean of $61.72 \pm$ $22.84 \%$.

Six-minute walking distance ranged from 189 to 459 $\mathrm{m}$, with mean of $285.91 \pm 81.07 \mathrm{~m}$.

The weight of our patients ranged from 15 to $45 \mathrm{~kg}$ (mean of $25.28 \pm 8.68 \mathrm{~kg}$ ), with $52.5 \%$ being underweight. Their height ranged from 99 to $160 \mathrm{~cm}$ (mean of $127.9 \pm 17.31 \mathrm{~cm}$ ), with $72.5 \%$ being stunted, while their BMI ranged from 11.34 to $20.27 \mathrm{~kg} / \mathrm{cm} 2$ (mean of 15.09

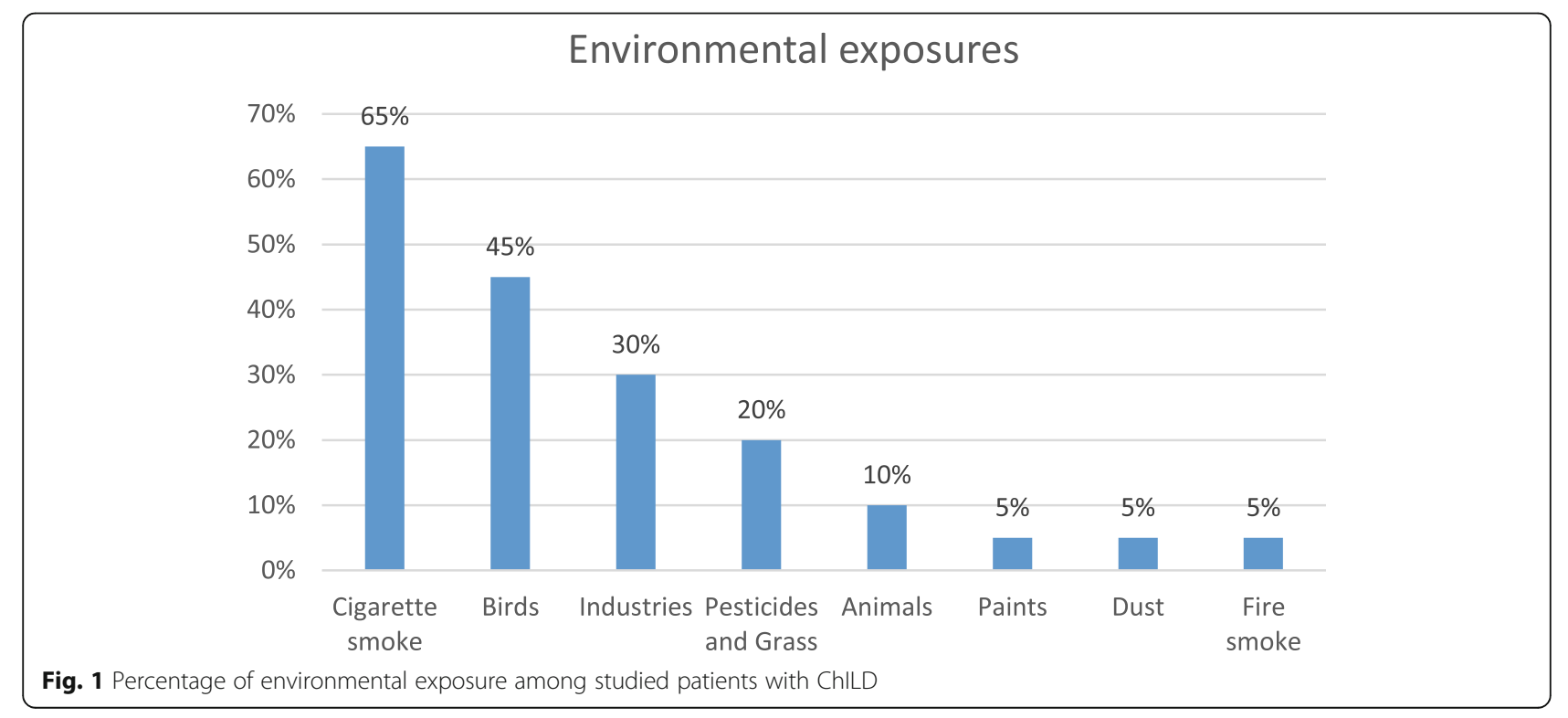




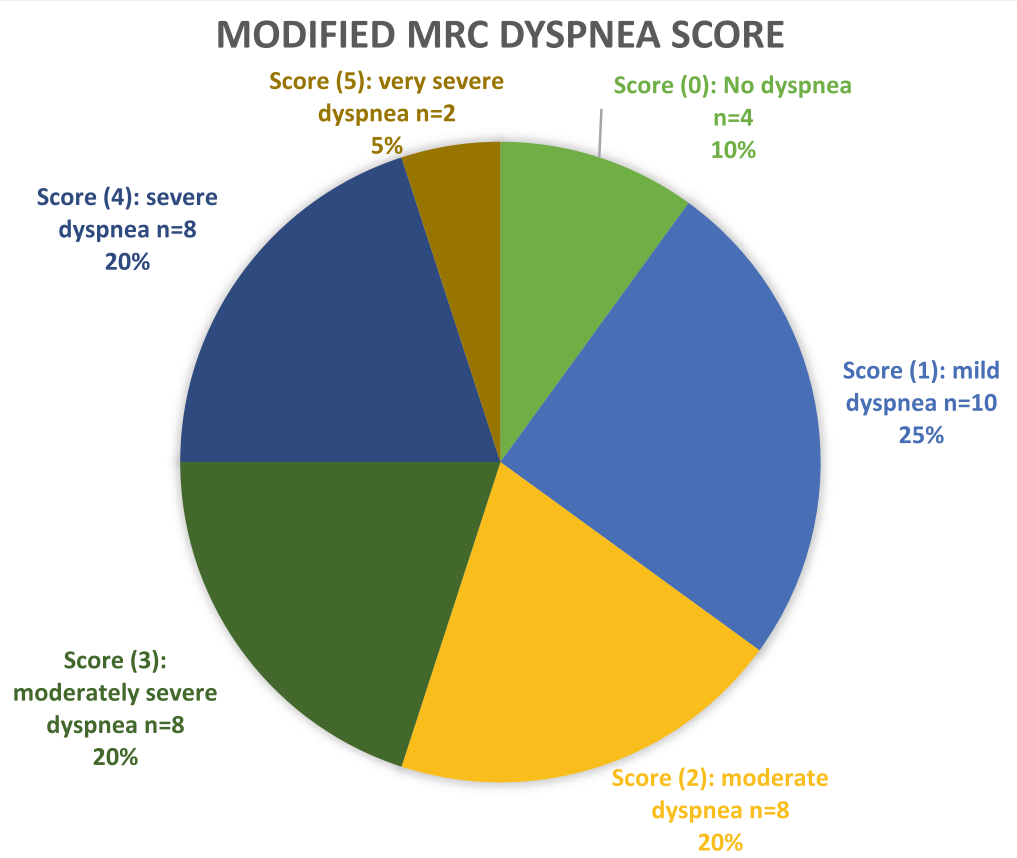

Fig. 2 Pie chart of modified MRC dyspnea score of chILD in Egyptian patients

$\pm 2.07 \mathrm{~kg} / \mathrm{cm} 2$ ), with $42.5 \%$ being thin (Table 2). Concerning hematological abnormalities, $60 \%$ of the patients had anemia, $25 \%$ had leukocytosis, and $35 \%$ had thrombocytosis.

Two of our studied patients (5\%) died during the period of our study. Both of them were females, aging 7 and 12 years. Both of them were common in their exposure to birds and cigarette smoke; they were underweight, stunted, with low BMI, and anemic with leukocytosis. Also, both had ILD severity score $\geq 4$, HRCT score of 3, moderately severe and severe restrictive pattern in spirometry, and decreased airway reactance by IOS (Table 3).

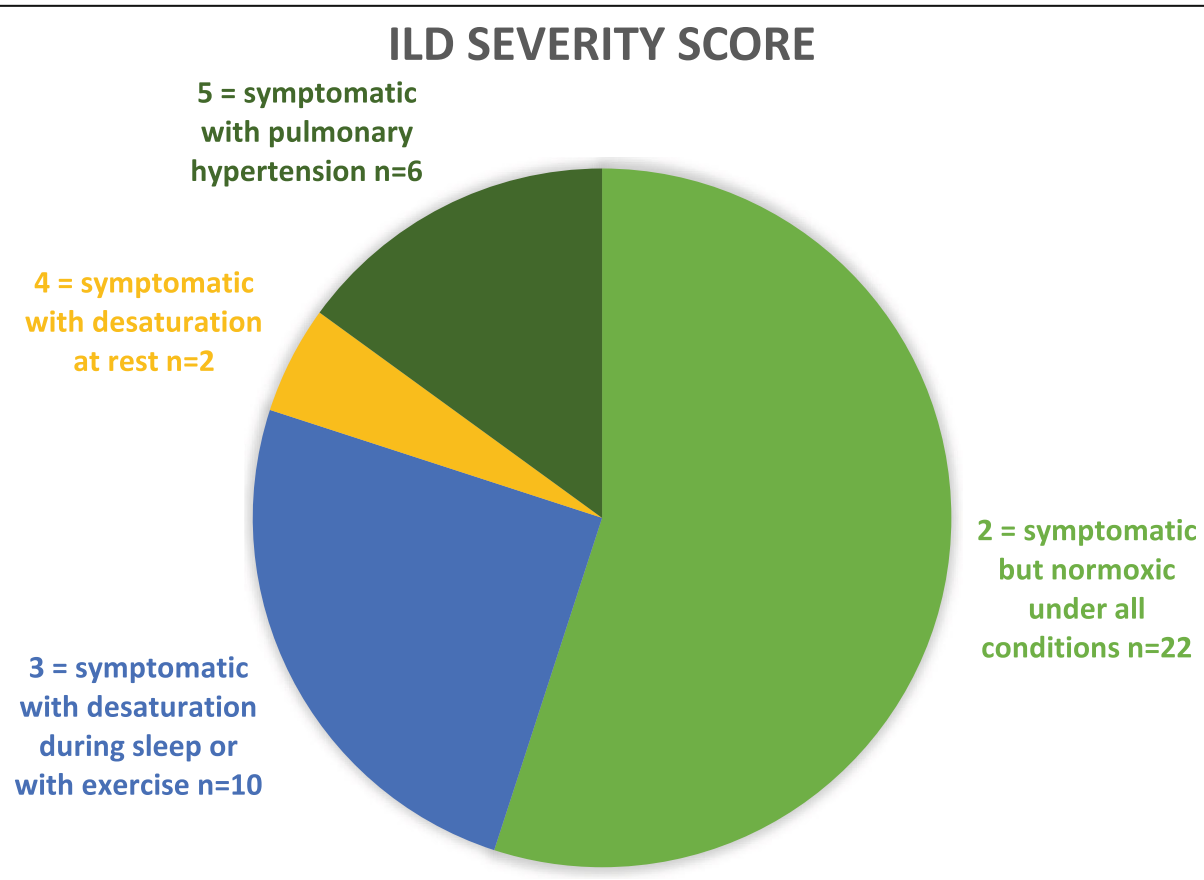

Fig. 3 Pie chart of ILD severity score of chILD in Egyptian patients 


\section{HRCT SCORE}

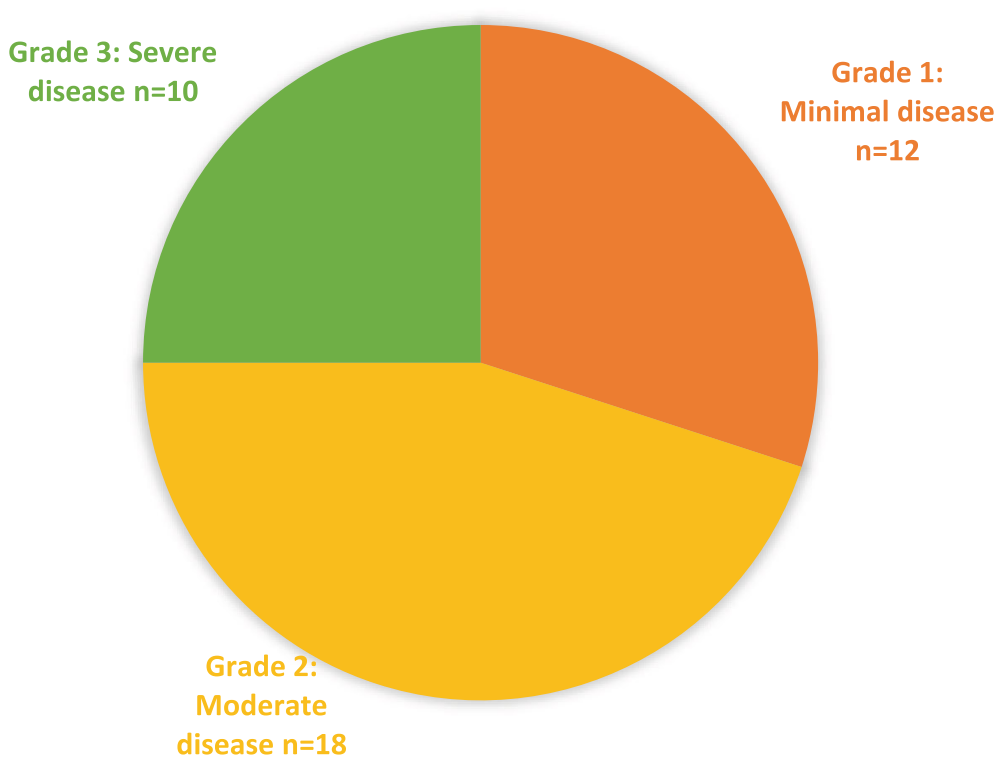

Fig. 4 Pie chart of HRCT score of chILD in Egyptian patients

\section{Discussion}

In our study, 18 children with interstitial lung diseases had history of exposure to birds. Pigeon exposure was found in 6 patients (33.33\% of those exposed to birds). Stauffer-Ettlin et al. [12] reported that up to $22 \%$ of pigeon breeders develop lung diseases, and Cramer et al. [13] mentioned that there is $56 \%$ increased risk of developing interstitial lung diseases among those exposed to pigeon. Another study done in Egypt including adult and pediatric patients with diffuse parenchymal lung disease showed that $73 \%$ of them were raising birds at home [14]. In addition, Saha [15] has mentioned increased risk of ILD among farm workers, poultry workers, bird fanciers, pigeon breeders, and home environment (in rural areas). Morell et al. [16] diagnosed 86 patients as BFL during the period 1977-2003, of which 7 (8\%) were in the pediatric age. Development of chILD after birds' exposure occurs when the birds' antigens trigger the development of immunoglobulin $G$ that results in formation of antigen-antibody reaction or immune complex that accumulates in the lung leading to hypersensitivity pneumonitis (HP) that is considered as a type of interstitial lung diseases; this raises the importance of taking the history of exposure to birds as it is usually missed by many physicians [12, 17]. In the UK, bird fancier's lung is the most common form of HP. If not treated, HP is usually progressive leading to pulmonary fibrosis and increased mortality [18]. There is a clear link between cigarette smoke and induction of interstitial lung diseases; however, the responsible substances in cigarette smoke are not identified [19]. But interstitial lung disease is now arising in pediatrics as a result of exposure to passive smoking, most of them are in the form of respiratory bronchiolitis associated interstitial lung diseases (RB-ILD) [20]. Moreover, toxic substances of

Table 2 Anthropometric measures of Egyptian patients with child

\begin{tabular}{|c|c|c|c|c|c|}
\hline \multicolumn{2}{|l|}{ BMI for age } & \multicolumn{2}{|l|}{ Weight for age } & \multicolumn{2}{|l|}{ Height for age } \\
\hline$Z$ score & $N(\%)$ & $Z$ score & $N(\%)$ & $Z$ score & $N(\%)$ \\
\hline Between 2 and 1 (overweight) & $1(2.5)$ & $\begin{array}{l}\text { Between - } 1 \text { and + } 2 \\
\text { (Normal) }\end{array}$ & $19(47.5)$ & $\begin{array}{l}\text { Between - } 1 \text { and + } 2 \\
\text { (normal) }\end{array}$ & $11(27.5)$ \\
\hline Between 0 and 1 (normal) & $22(55)$ & Between -2 and - 1 (mildly underweight) & $12(30)$ & $\begin{array}{l}\text { Between }-2 \text { and - } 1 \\
\text { (mildly stunted) }\end{array}$ & $15(37.5)$ \\
\hline Between -2 and -3 (thin) & $14(35)$ & Between -3 and -2 (moderately underweight) & $5(12.5)$ & $\begin{array}{l}\text { Between }-3 \text { and }-2 \\
\text { (moderately stunted) }\end{array}$ & $8(20)$ \\
\hline Below - 3 (very thin) & $3(7.5)$ & $<-3$ (severely underweight) & $4(10)$ & $<-3$ (severely stunted) & $6(15)$ \\
\hline
\end{tabular}


Table 3 Demographic data of the two dead patients during our study

\begin{tabular}{|c|c|c|}
\hline Demographic data & Patient 1 & Patient 2 \\
\hline Age (years) & 12 & 7 \\
\hline Sex & Female & Female \\
\hline $\begin{array}{l}\text { Age of onset of symptoms } \\
\text { (years) }\end{array}$ & 3 & 5 \\
\hline Disease duration (years) & 10 & 3 \\
\hline Frequency of hospital admission (/year) & 2 & 4 \\
\hline Exposure & $\begin{array}{l}\text { Birds } \\
\text { Cigarette smoke } \\
\text { Fire smoke }\end{array}$ & $\begin{array}{l}\text { Birds } \\
\text { Cigarette smoke }\end{array}$ \\
\hline Symptoms & $\begin{array}{l}\text { Cyanosis } \\
\text { Dyspnea } \\
\text { Cough } \\
\text { Clubbing } \\
\text { Expectoration }\end{array}$ & $\begin{array}{l}\text { Cyanosis } \\
\text { Dyspnea } \\
\text { Cough } \\
\text { Clubbing }\end{array}$ \\
\hline Weight for age (Z-score) & $<-3$ & Between -3 and -2 \\
\hline Height for age (Z-score) & $<-3$ & Between -3 and -2 \\
\hline BMI for age (Z-score) & $<-3$ & Between -3 and -2 \\
\hline Respiratory rate (breath/min) & 53 (Tachypneic for age) & 62 (Tachypneic for age) \\
\hline Heart rate (beat/min) & 104 (Tachycardic for age) & 113 (Tachycardic for age) \\
\hline Modified MRC dyspnea score & 4 & 3 \\
\hline Chest examination & Fine and coarse crepitations & Fine crepitations \\
\hline Heart examination & Accentuated second heart sound & Normal \\
\hline Oxygen saturation at rest (\%) & 92 & 93 \\
\hline ILD severity score & 5 & 4 \\
\hline Total leukocyte count $\left(\times 10^{3} / \mu l\right)$ & 18.7 & 26.9 \\
\hline Hemoglobin $(g / d l)$ & 11.3 & 10.9 \\
\hline Platelets count $\left(\times 10^{3} / \mu \mathrm{l}\right)$ & 392 & 369 \\
\hline Chest x-ray & Reticulonodular pattern & Reticulonodular pattern \\
\hline HRCT score & 3 & 3 \\
\hline FEV1 \% of predicted & 46.4 & 59.4 \\
\hline FVC $\%$ of predicted & 50.7 & 52.7 \\
\hline FEV1/FVC & 80.92 & 111.3 \\
\hline DLCO-SB (\%) & Could not be performed & Could not be performed \\
\hline
\end{tabular}

$B M I$ body mass index, MRC modified Medical Research Center, ILD interstitial lung diseases, HRCT high-resolution computerized tomography, FEV1 forced expiratory volume in $1 \mathrm{~s}$, FVC forced vital capacity, DLCO-SB diffusion of lung to carbon monoxide (single breath)

more than 4000 chemicals generated from combustion of tobacco plant leaves are known to cause several respiratory diseases and are associated with an increase in respiratory infections $[21,22]$.

Pesticides including insecticides, fungicides, or herbicides are commonly used in agricultural areas and are considered a major occupational hazard. Studies show that organophosphate causes serious pulmonary effects that lead to significant deterioration in lung functions whether the route of entry to the body is through the skin or gastrointestinal or respiratory tracts [23]. Exposure to animals can cause interstitial lung disease not only by causing inflammation in the lung by animal feathers, secretions, urine, and feces but also by increased risk of zoonotic infections by multidrug resistant organisms whether bacterial, viral, or fungal that may end up by lung fibrosis [23]. Our study showed female predominance, with male to female ratio $2: 3$; this goes with the study of Morell et al. [16] on BFL that showed female predominance, with male to female ratio 1:3 and also Selman et al. [24] who had $89 \%$ of their patients were females. The slight female predominance in children with ILD was also noticed by Nathan et al. [25]. However, Clement et al. [26] and Annamalai et al. [27] noticed more male predominance. Also, Wells and Hirani [18] found male predominance among patients with BFL. This difference may be related to different cultural backgrounds, epigenetics, and different age groups 
studied. Also, another Egyptian study showed that females working in farming and birds breeding, exposed to animals, dust or, pesticides, have increased risk of developing ILD [28]

The most frequent symptoms and signs were also studied by Clement et al. [26] who reported that tachypnea was observed in $80 \%$ of patients and was usually the earliest and most common respiratory symptom followed by cough (75\%), fever (33\%), and faltering growth (37\%). The frequent 206 clinical findings in his study were crepitations (44\%), cyanosis (28\%), and clubbing (13\%) [26].

The causes of faltering growth are mostly multifactorial and include repeated chest infections, anorexia, and increased caloric requirement attributed to increased work of breathing [29]. Low BMI is associated to poor prognosis and decreased survival [30]. Efforts should be directed not only to medical treatment of Egyptian children with chILD, but also to improve their nutritional status, because it definitely can improve their quality of life and increase survival. More than $60 \%$ of the patients exposed to birds had MRC dyspnea score grades 0 to 1 , while $27.78 \%$ had scores $3-4$. This goes with the study of Morell et al. [16] who found that $25 \%$ of the patients had grades 3-4 at the time of diagnosis.

The commonest HRCT finding was ground glass appearance $(80 \%)$, and this coincides with the findings of Vijayasekaran et al. [31] who mentioned that ground glass opacification is the commonest radiological abnormality, seen in all the cases, followed by interstitial thickening in $53.84 \%$ of the cases and interlobular septal thickening and traction bronchiectasis in $23.07 \%$ of the cases. But Sankar et al. [32] mentioned that ground glass appearance was as common as septal thickening. In the study of Morell et al. [16], 68\% of the patients with BFL had ground glass appearance which was also considered the commonest radiological finding. HRCT represents the method of choice for the diagnosis of ILD [33] as 30\% of our patients had normal chest $\mathrm{x}$-ray although there were positive findings in HRCT. This agrees with Vijayasekaran et al. [31] who reported that $\mathrm{x}$-rays revealed abnormalities suggestive of ILD in only $75 \%$ of the cases. Also Ryu et al. [34] mentioned that $10 \%$ of patients with ILDs had normal chest radiograph early in the course of disease and Palmucci et al. [35] concluded that chest $\mathrm{x}$-rays have low diagnostic specificity and can sometimes be normal.

DLCO done to our patients had a mean of $61.72 \pm$ $22.84 \%$ of the predicted values; this was higher than the results of Inage et al. [36] and Liu et al. [37] (mean \pm SD; $40.7 \pm 6.7$ and $45.8 \pm 2.6$, respectively) [36]; this is probably because our results represent the diffusion of the lung of patients with better respiratory effort capable of performing the test and not including very young and severely dyspneic patients. The study done by Fan and Kozinetz [38] revealed that age of onset, underweight, clubbing, crepitations, family history of ILD, or duration of illness were not associated with decreased survival, but survival was only related to the ILD severity score which was high in our study in both dead patients (scores 4 and 5) [37]. Annamalai et al. [27] concluded that ILD severity score of 5 (denoting pulmonary hypertension) has 5 years' survival of $38 \%$. Also, the study of Collum et al. [39] revealed that pulmonary hypertension complicating patients with interstitial lung disease increases morbidity and mortality [39].

\section{Conclusion}

Exposure to cigarette smoke and birds were found in 65 and $45 \%$ of children with interstitial lung disease respectively and they represent significant environmental hazard.

\section{Abbreviations \\ BFL: Bird fancier's lung; BMI: Body mass index; chILD: Childhood interstitial lung diseases; CT: Computed tomography; DLCO: Diffusion capacity of the lung to carbon monoxide; FEV1: Forced expiratory volume in first second; FVC: Forced vital capacity; HP: Hypersensitivity pneumonitis; HRCT: High- resolution computed tomography; ILD: Interstitial lung disease; IOS: Impulse oscillometry; IPF: Idiopathic pulmonary fibrosis; MRC: Modified Medical Research Council; R5Hz: Resistance at $5 \mathrm{~Hz} ; \mathrm{R} 20 \mathrm{~Hz}$ : Resistance at $20 \mathrm{~Hz}$; X5 $\mathrm{Hz}$ : Reactance at $5 \mathrm{~Hz}$}

\section{Acknowledgements \\ Thanks to patients of Chest clinic, Children's Hospital, Ain Shams University, who willingly participated in the study.}

\section{Authors' contributions}

SI collected the data of patients, assessed them clinically, and wrote the manuscript, AH performed the statistical studies, and TK directed the whole work and revised the manuscript. All authors have read and approved the manuscript.

Funding

This research did not receive any funding.

\section{Availability of data and materials}

Data and materials are available upon request, saved only for ethical considerations.

\section{Ethics approval and consent to participate}

Approval of the medical ethical committee of Children's Hospital, Ain Shams University, was taken before the study. Written informed consent was obtained from a parent or legal guardian of participants under 16 years old. The committee's reference number is not available.

Consent for publication

Not applicable.

\section{Competing interests}

No conflict of interest

\section{Author details}

${ }^{1}$ Pediatric Department, Faculty of Medicine, Ain Shams University, Cairo 11591, Egypt. ${ }^{2}$ Community, Environmental and Occupational Medicine Department, Faculty of Medicine, Ain Shams University, Cairo, Egypt. 
Received: 30 September 2020 Accepted: 21 December 2020

Published online: 07 January 2021

\section{References}

1. Lee EY. Pediatric Interstitial (Diffuse) Lung Disease (2019) Imaging in Pediatric Pulmonology. 145-197

2. Cazzato S, Palmo E, Ragazzo V, Ghione S (2013) Interstitial lung disease in children. Early Human Development. 89:S39-S43

3. Spagnolo P and Bush A (2016) Interstitial Lung Disease in Children Younger Than 2 Years. Pediatrics. 137(6):e20152725

4. Travis WD, Costabel U, Hansell DM, TKing TE, Lynch DA, Nicholson AG et a (2013) An Official American Thoracic Society/European Respiratory Society Statement: Update of the International Multidisciplinary Classification of the Idiopathic Interstitial Pneumonias. Am J RespirCrit Care Med. 188(6):733-748

5. Perez-Padilla R, Schilmann A, Riojas-Rodriguez H (2010) Respiratory health effects of indoor air pollution. Int J Tuberc Lung Dis. 14(9):1079-1086

6. Fan LL, Kozinetz CA, Deterding RR, Brugman (1998) Evaluation of a diagnostic approach to pediatric interstitial lung disease. Paediatrics. 101: 82-85

7. Papiris SA, Daniil Z, Malagari K et al (2005) The Medical Research Council dyspnea scale in the estimation of disease severity in idiopathic pulmonary fibrosis. Respir Med. 99:755-761

8. Fessi R, Ourari B, Amar JB, Zaibi H, Azzabi S, Baccar MA, Aouina H (2018) High-resolution computed tomography fibrosis score and pulmonary function tests in interstitial lung disease: Is there any correlation? Eur Respir J. 52:PA2926.

9. American Thoracic Society (ATS) statement (2002) Guidelines for the sixminute walk test. Am J Respir Crit Care Med. 166:111-117

10. Holland AE, Dowman L, Fiore J, Brazzale D, Hill CJ, McDonald CF (2014) Cardiorespiratory responses to 6-minute walk test in interstitial lung disease: not always a submaximal test. BMC Pulm Med. 14:136

11. Hayes D Jr, Wilson KC, Krivchenia K, et al. (2019) Home Oxygen Therapy for Children. An Official American Thoracic Society Clinical Practice Guideline. Am J Respir Crit Care Med. 199(3):e5-e23

12. Stauffer-Ettlin M, Pache JC et al (2006) Bird breeder's disease: a rare diagnosis in young children. Eur J Pediatr. 165(1):55-61

13. Cramer C, Schlunssen V, Bendstrup E, Stokholm ZA, Vestergaard JM, Frydenberg $\mathrm{M}$ et al (2016) Risk of hypersensitivity pneumonitis and interstitial lung diseases among pigeon breeders. The European respiratory journal. 48(3):818-825

14. AbouYoussef HA, Sabri YYY, El Essawy AF, Mohamed Hussein SA, Ibrahim EK, Ahmed MI (2019) Clinico-radiography and pulmonary functional assessment of patients 305 with diffuse parenchymal lung diseases in Al-Fayoum Governorate. Egypt J Bronchol. 13(1):125-131

15. Saha K (2014) Interstitial lung disease: Diagnostic approach. J Assoc Chest Physicians 2(1):3-15

16. Morell F, Roger A, Reyes L, Cruz MJ, Murio C, Muñoz X (2008) Bird fancier's lung: a series of 86 patients. Medicine (Baltimore). 87(2):110-130

17. Habra B, AbdulWahab A (2018) A rare pediatric case of severe bird fancier's lung presented with viral pneumonitis-like picture. Children (Basel). 5(11): 149

18. Wells AU, Hirani N (2008) Interstitial lung disease guideline: The British Thoracic Society in collaboration with the Thoracic Society of Australia and New Zealand and the Irish Thoracic Society. Thorax. 63:V1-V58

19. Hagmeyer $L$, Randerath W (2015) Smoking-related interstitial lung disease. Dtsch Arztebl Int. 112(4):43-50

20. Sismanlar T, Aslan AT, Turktas H, Memis L, Griese M (2015) Respiratory Bronchiolitis-Associated Interstitial Lung Disease in Childhood: New Sequela of Smoking. Pediatrics. 136(4):e1026-9

21. Seguel JM, Merrill R, Seguel D, Campagna AC (2016) Indoor Air Quality. Am J Lifestyle Med. 11(4):284-295

22. Patel RR, Ryu JH, Vassallo R (2008) Cigarette smoking and diffuse lung disease. Drugs. 68(11):1511-1527

23. Nordgren TM, Charavaryamath C (2018) Agriculture occupational exposures and factors affecting health effects. Curr Allergy Asthma Rep. 18(12):65

24. Selman M, Lacasse Y, Pardo A, Cormier Y (2010) Hypersensitivity pneumonitis caused by fungi. Proc Am Thorac Soc. 7:229-236

25. Nathan N, Taam RA, Epaud R, Delacourt C, Deschildre A, Reix P et al (2012) A national internet-linked based database for pediatric interstitial lung diseases: The French network. Orphanet J Rare Dis 7:40
26. Clement A, Nathan N, Epaud R, Fauroux B, Corvol H (2010) Interstitial lung diseases in children. Orphanet J Rare Dis. 5:22

27. Annamalai M, Thula SA, Naidoo V, Jeena PM (2014) A Clinical Approach To Childhood Interstitial Lung Disease. The Paediatric Quarterly. 5:3

28. Awadalla NJ, Hegazy A, Elmetwally RA, Wahby I (2012) Occupational and environmental risk factors for idiopathic pulmonary fibrosis in Egypt: a multicenter case-control study. Int J Occupational Environmental Med. 3: 107-116

29. Ibrahim HM, Kamel TB, Abdel-Salam NMS, Abu-Ata SR (2011) Study of auditory function in children with chronic lung diseases. Int J Pediatric Otorhinolaryngol 75:39-42

30. Kulkarni T, Yuan K, Tran-Nguyen TK et al (2019) Decrements of body mass index are associated with poor outcomes of idiopathic pulmonary fibrosis patients. PLoS One. 14(10):e0221905

31. Vijayasekaran D, Giridhar S, Gowrishankar NC, Nedunchelian K, Senguttuvan M (2006) Pediatric 350 interstitial lung disease. Indian Pediatr 43:899-903 351

32. Sankar J, Pillai MS, Sankar MJ, Lodha R, Kabra SK (2012) Clinical profile of interstitial lung 352 disease in Indian children. Indian Pediatrics. 50:57-58

33. Saketkoo LA, Ascherman DP, Cottin V, Christopher-Stine L, Danoff SK, Oddis CV (2010) Interstitial lung disease in idiopathic inflammatory myopathy. CurrRheumatol Rev. 6(2):108-119

34. Ryu JH, Daniels CE, Hartman TE, Yi ES (2007) Diagnosis of Interstitial Lung Diseases. Mayo Clinic Proceedings. 82(8):976-986

35. Palmucci S, Roccasalva F, Puglisi S, et al. (2014) Clinical and radiological features of idiopathic interstitial pneumonias (IIPS): a pictorial review. Insights Imaging. 5(3):347-364

36. Inage M, Nakamura H, Kato S, Saito H, Abe S, Hino T, Tomoike H (2000) Levels of cytokeratin 19 fragments in bronchoalveolar lavage fluid correlate to the intensity of neutrophil and eosinophil-alveolitis in patients with idiopathic pulmonary fibrosis. Resp Med. 94:155-160

37. Liu QX, Zheng JP, Xie YQ, Guan WJ, Jiang CY, An JY, Yu XX, Liu WT, Gao Y. (2013) Single-breath and rebreathing methods for measurement of pulmonary diffusing function: a comparative study. Zhonghua Jie $\mathrm{He} \mathrm{He} \mathrm{Hu}$ Xi Za Zhi. 36(7):510-5

38. Fan LL and Kozinetz CA (1997) Factors influencing survival in children with chronic interstitial lung disease. Am J Respir Crit Care Med. 156:939-42

39. Collum SD, Amione-Guerra J, Cruz-Solbes AS, et al. (2017) Pulmonary Hypertension Associated with Idiopathic Pulmonary Fibrosis: Current and Future Perspectives. Can Respir J. 2017:1430350

\section{Publisher's Note}

Springer Nature remains neutral with regard to jurisdictional claims in published maps and institutional affiliations.

\section{Submit your manuscript to a SpringerOpen ${ }^{\circ}$ journal and benefit from:}

- Convenient online submission

- Rigorous peer review

- Open access: articles freely available online

- High visibility within the field

- Retaining the copyright to your article

Submit your next manuscript at $>$ springeropen.com 